\title{
Práticas psicológicas e cuidados paliativos no contexto pandêmico: um estudo das representações sociais
}

\author{
Psychological practices and palliative care in the pandemic context: a study of social \\ representations \\ Prácticas psicológicas y cuidados paliativos en el contexto de la pandemia: un estudio de las \\ representaciones sociales
}

Recebido: 07/02/2022 | Revisado: 16/02/2022 | Aceito: 20/02/2022 | Publicado: 02/03/2022

Fabrycianne Gonçalves Costa ORCID: https://orcid.org/0000-0003-2903-7555 Centro Universitário UNIESP, Brasil E-mail: prof1588@iesp.edu.br

Gláucia Maria Matos de Castro ORCID: https://orcid.org/0000-0003-4750-0419 Centro Universitário UNIESP, Brasil E-mail: glaucastro34@gmail.com

Maria da Penha de Lima Coutinho ORCID: https://orcid.org/0000-0003-3961-2402 Centro Universitário UNIESP, Brasil E-mail:mplcoutinho@gmail.com

Márcio de Lima Coutinho

ORCID: https://orcid.org/0000-0003-1092-7566 Centro Universitário UNIESP, Brasil E-mail:prof1589@iesp.edu.br

\begin{abstract}
Resumo
Cuidados paliativos são caracterizados como uma assistência desempenhada por uma equipe multidisciplinar com o propósito de proporcionar a melhoria da qualidade de vida do paciente e seus familiares perante uma doença que ameace a vida. Nesse sentido, objetivou-se compreender as representações sociais acerca dos cuidados paliativos de competência do psicólogo hospitalar durante a pandemia da Covid-19. Participaram do estudo 16 psicólogos hospitalares, com idades entre 23 a 60 anos $(M=36,56$; $D P=11,89)$, sendo a maioria do gênero feminino, os quais responderam a um questionário sociodemográfico e à entrevista semiestruturada. Os dados foram processados pelos softwares SPSS e IRAMUTEQ e analisados por meio da estatística descritiva, análise lexical, e nuvem de palavras. Os resultados evidenciaram que o conhecimento sobre os cuidados paliativos esteve ancorado no saber teórico e prático envolto por aspectos implicativos no contexto pandêmico. Dessa forma espera-se que este trabalho contribua com novos conhecimentos que possam melhorar a prática do psicólogo hospitalar.
\end{abstract}

Palavras-chave: Representações sociais; Cuidados paliativos; Psicólogo hospitalar; Covid-19.

\begin{abstract}
Palliative care is characterized as assistance performed by a multidisciplinary team with the purpose of providing an improvement in the quality of life of patients and their families in the face of a life-threatening disease. In this sense, the objective was to understand the social representations about palliative care within the competence of hospital psychologists during the Covid-19 pandemic. Sixteen hospital psychologists, aged between 23 and 60 years $(\mathrm{M}=$ 36.56; SD = 11.89), participated in the study, most of them female, who answered a sociodemographic questionnaire and a semi-structured interview. Data were processed by the SPSS and IRAMUTEQ software and impediment through descriptive statistics, lexical analysis, and word cloud. The results showed that knowledge about palliative care was anchored in the theoretical and practical knowledge involved by implicative aspects in the pandemic context. Thus, it is expected that this work will contribute with new knowledge that will improve the practice of hospital psychologists.
\end{abstract}

Keywords: Social representations; Palliative care; Hospital psychologist; Covid-19.

\section{Resumen}

Los cuidados paliativos se caracterizan como la asistencia realizada por un equipo multidisciplinario con el propósito de mejorar la calidad de vida de los pacientes y sus familias frente a una enfermedad que amenaza la vida. En ese sentido, el objetivo fue comprender las representaciones sociales sobre los cuidados paliativos del psicólogo 
hospitalario durante la pandemia de la Covid-19. Participaron en el estudio 16 psicólogas hospitalarias, con edades entre 23 y 60 años $(M=36,56$; DT= 11,89), en su mayoría mujeres, que respondieron un cuestionario sociodemográfico y una entrevista semiestructurada. Los datos fueron procesados por el software SPSS e IRAMUTEQ y analizados mediante estadística descriptiva, análisis léxico y nube de palabras. Los resultados mostraron que el conocimiento sobre cuidados paliativos estaba anclado en conocimientos teóricos y prácticos rodeados de aspectos implicativos en el contexto de la pandemia. Así, se espera que este trabajo aporte nuevos conocimientos que puedan mejorar la práctica del psicólogo hospitalario.

Palabras clave: Representaciones sociales; Cuidados paliativos; Psicólogo hospitalario; Covid-19.

\section{Introdução}

Na última década o SARS-CoV-2, conhecido como Corona vírus disease (Covid-19) é a segunda pandemia que acomete o mundo, essa por sua vez considerada mais contagiosa e devastadora em comparação a primeira, denominada Influenza A (H1N1), em 2009. A Organização Mundial da Saúde notificou a Covid-19 e a classificou como infecto-contagiosa, progredindo em muitos casos para infecções respiratórias graves e sendo a causa de milhares de óbitos. Os primeiros casos foram na região de Wuhan (China) em um mercado de frutos do mar, alastrando-se em pouco tempo por todo mundo (Brasil, 2020).

Os pacientes relataram sintomas como febre, tosse seca, dificuldade para respirar que aumentava gradativamente, dor de cabeça, pneumonia, febre, e mesmo diante ao tratamento alguns pacientes não obtinham êxito demonstrando através de exames de imagem comprometimento do pulmão e dano alveolar, causando até mesmo a morte (Zhou et al., 2020).

Desde então, o mundo atravessa uma crise motivada pelo novo Coronavírus, desencadeada ao avanço significativamente rápido da doença, e a OPAS/OMS Organização Mundial da Saúde qualificou como pandemia no dia de 11 de março de 2020. desde então a Covid-19 é considerada um dos maiores desafios sanitários mundiais do século (Barreto et al., 2020).

Os serviços de saúde experienciaram um crescimento significativo no fluxo de pessoas que procuraram atendimento em virtude dos sintomas causados pela Covid-19. Em diagnósticos positivos ao vírus imediatamente recorria-se aos protocolos de segurança, como isolamento social, podendo ser realizado em seu próprio domicílio no caso de sintomas leves, porém, em casos com agravamento, demandou-se a necessidade de internação para tratamento intensivo, gerando superlotação de hospitais públicos e privados.

A pandemia da Covid-19 trouxe muitas mortes em decorrência a agressividade do vírus, e em paralelo também acarretou em uma série de danos emocionais e prejuízos a saúde mental das pessoas, a ansiedade e o medo da contaminação pelo vírus, o isolamento social, as mortes repentinas, causando sofrimento coletivo. Em situações de alto estresse, como uma pandemia, nossa mente trabalha em hipervigilância, e nossa psique ativa o modo sobrevivência, com o passar da situação de estresse, ansiedade e medo prolongado, é possível o aparecimento dos transtornos mentais refletindo a situação vivenciada (Brunoni, 2020).

Esses fatores resultam em diferentes níveis de pressão psicológica, que podem desencadear sentimentos de solidão e desamparo e uma série de estados emocionais disfóricos, como estresse, irritabilidade, distúrbios do sono, fadiga mental e desespero. Nessa conjuntura, a importância de a psicologia estar presente em situações de crise torna-se ainda mais evidente, sendo o principal papel do psicólogo, oferecer suporte emocional, apoio e acolhimento às pessoas que se encontram em sofrimento psíquico (Sá, 2020).

Sabendo da importância do psicólogo no manejo e na prevenção de transtornos mentais, para atenuar impactos emocionais diante de circunstâncias traumáticas vivenciadas, em todas as suas áreas de atuação. Diante desse pensamento, podemos afirmar que o psicólogo hospitalar em situações emergenciais, como a pandemia do Covid-19, sistematizando a realização de grupos operativos, realizando treinamentos e clarificando o papel de cada profissional, além de estimular a 
realização de atividades para a diminuição do estresse visto que em profissionais da área da saúde o nível de estresse é elevado (Chiattone, 2000).

A presença do psicólogo traz aos familiares e ao paciente a certeza de um amparo, de um conforto de alguém que compreende o processo que todos estão passando e que ao mesmo tempo contribui para tratar as demandas, fazendo com que todos aceitem com mais tranquilidade a morte (Rodrigues, Souza, 2015). Nesse viés ao adentrar na importância de uma equipe multiprofissional é importante estar preparada para intervir no cuidado curativo, e também apoiar-se na subjetividade daquela pessoa, predispondo-se a entender suas necessidades e respeitar sua individualidade, aprofundando onde a medicina é limitada ou impossibilitada, valendo-se da escuta qualificada e acolhimento humanizado, fazendo com que aquele paciente e sua família se sintam assistidos. E assim preparados para o início de um processo que pode ser breve ou longo, independente do estágio clínico da doença e resposta do tratamento.

Entre as atribuições que compete ao psicólogo hospitalar, pode-se evidenciar a prática dos Cuidados Paliativos, tendo como prioridade, proporcionar ao paciente uma melhor qualidade de vida, mesmo diante do risco de morte e/ou inviabilidade de cura, alívio dos sintomas, acolhimento a família, e apoio e equipe, integrando todos os aspectos físicos, emocionais, psicossociais e espirituais. Os cuidados paliativos consolidaram-se no Brasil em 1980 pela Academia Nacional de Cuidados Paliativos (ANCP), e sua ratificação em 1990 (OMS) e ampliação do conceito em 2002 (OMS, 2021). A presença desse profissional poderá ser decisiva na resolução de conflitos existenciais que possivelmente possam existir entre família, equipe e paciente, nessa situação de terminalidade imposta pela doença (Domingues et al., 2013).

Quando realizados, ainda que em situações de emergência e catástrofes, à prática em CP é reconhecida como ferramenta importante para o alívio dos desconfortos das dores, físico e emocional. Uma vez que em situações emergentes acontecem, objetiva-se salvar o maior número de vidas possível, resultando em uma dinâmica mecanicista nos atendimentos, dificultando uma atenção mais sensível aos fatores emocionais. Nesse contexto há a necessidade de um profissional que intervenha na subjetividade, promovendo acolhimento e apoio psicológico. É papel do psicólogo hospitalar o apoio à família deste paciente, oferecendo acolhimento, e em casos de óbito de seu familiar, prestar total apoio na elaboração desse luto (Hermes \& Lamarca, 2013). A presença do profissional da psicologia, poderá ser decisiva na mediação e resolução de conflitos que possam ocorrer envolvendo a família, equipe e o paciente, principalmente em situações que envolvem decisões sobre procedimentos para o tratamento e até mesmo relacionado a terminalidade (Domingues et al., 2013). Quando se fala em CP, vale frisar que sua prática não cessa com a morte daquele paciente, considerando que após o óbito do paciente, se inicia o processo da elaboração do luto, existindo a necessidade de acolhimento aos familiares daquele paciente. A terminalidade é um processo doloroso e delicado, mesmo sabendo que a morte é um percurso natural ao ciclo vital.

No decurso dos séculos, era comum as pessoas morrerem no seio familiar, em suas casas, mas com o passar dos anos, esse processo passou a ocorrer com mais frequência nos hospitais (Incontri \& Santos, 2009). Elizabeth Kübler-Ross (2017), pioneira em descrever as atitudes e reações emocionais que pacientes com doenças terminais vivenciam antes de morrer, são eles: negação, raiva, barganha, depressão e aceitação, porém esses estágios nem sempre acontecem nesta ordem, isso dependem de como o paciente entende o processo de terminalidade diante de sua trajetória de vida.

Diante ao cenário de pandemia, considerando que essas mortes causadas pelo Covid-19, sucederam repentinamente, considerando o intervalo entre a contaminação, adoecimento, diagnóstico até a morte, e impossibilitando costumes como: visitas e rituais fúnebres tradicionais, dificultando as interações entre pessoas que possuem relações de estreito vínculo, dificultando o apoio e a comunicação, fez com que a Covid-19, fosse conhecida como uma doença solitária, já que o paciente com diagnóstico positivo tivesse que enfrentar sozinho seu processo de adoecimento trazendo mais dor e angústia a todos.

Sabendo das dificuldades enfrentadas pelos profissionais de saúde para o desempenho de suas atividades laborais, tanto no número insuficiente de pessoal no quadro, falta de insumos e equipamentos, a situação de caos se intensificou com a 
chegada da pandemia, mesmo diante disso, a equipe multiprofissional se desdobrava para oferecer aos pacientes um atendimento o mais humanizado possível, Fundação Oswaldo Cruz (2020), e entende-se que em situações assim, é imprescindível a realização de um suporte psicológico dentro dessa equipe, e o psicólogo hospitalar desempenha esse papel, englobando tanto o apoio a equipe multiprofissional, pacientes e familiares

O psicólogo precisa ter muito claro que sua atuação no contexto hospitalar não é psicoterápica dentro dos moldes do chamado setting terapêutico. E como minimização do sofrimento provocado pela hospitalização, também é necessário abranger-se não apenas a hospitalização em si - em termos específicos da patologia que eventualmente tenha originado a hospitalização - mas principalmente as sequelas e decorrências emocionais dessa hospitalização (Truchart et al., 2003, p. 25).

É impreterível que o psicólogo hospitalar esteja alinhado aos demais membros da equipe multidisciplinar, assim, conseguirá ter uma visão abrangente de todo contexto daquele paciente e família, assim como perspectiva de prognóstico do seu quadro clínico e possíveis intervenções individuais, que em virtude da pandemia da Covid-19, algumas práticas precisaram ser readaptadas e adequadas para atender os novos e rígidos protocolos de segurança, e assim continuar oferecendo assistência psicológica e integral aos pacientes e familiares.

Dessa forma, para o conhecimento sobre as práticas da psicologia hospitalar voltada aos cuidados paliativos durante a pandemia da Covid-19, e entender sobre suas representações sociais, de forma científica e fundamentada, recorreu-se ao arcabouço teórico da Teoria das Representações Sociais, objetivando em especial compreender a interação entre sujeito/objeto e indivíduo/sociedade diante da problemática provocada por esse estudo (Farr, 2009; Sá, 1995).

Segundo Moscovici (2012, p. 46), as Representações Sociais (RS) "ocupam uma posição curiosa, em algum ponto entre conceitos, que têm como seu objetivo abstrair o sentido do mundo e introduzir nele ordem e percepções, que reproduzem no mundo de uma forma significativa". A construção das representações envolve dois processos formadores: a ancoragem e a objetivação, o que para Sá (2015), essas representações servem como um guia, ditando como comportamentos e práticas devem funcionar. Nesse sentido, a representação funciona como uma antecipação das ações, quando intervém na finalidade da situação, no tipo de atitude cognitiva a ser adotada pelos sujeitos sociais, revelando, assim, sua natureza prescritiva (Abric, 1994).

Para Moscovici (2012), a principal função da teoria das representações sociais é tornar familiar o que não é familiar, e as RS precisam obedecer a alguns critérios para que sejam consideradas representações sociais, sendo elas, quantitativo onde são compartilhadas por um número expressivo de pessoas, por exemplo grupos. Outro critério seria o genético, que seriam as que são construídas socialmente, onde o pensamento social é construído via relações sociais, e o funcional são guias para a comunicação para a ação. A ancoragem transfere o desconhecido para o esquema de referência, por meio da comparação e da interpretação; por sua vez, o processo de objetivação reproduz o desconhecido, entre o que é visível e tangível. Assim, surge uma RS ante um novo objeto, por meio da materialização de uma entidade abstrata, que foi ancorada pela classificação e pela nomeação (Moscovici, 2012).

Conforme essa perspectiva das funções existem dois processos básicos: a ancoragem e a objetivação. O primeiro, diz respeito ao significado que o sujeito fornece ao objeto, relacionando as práticas e valores que o grupo tem em comum. Já a objetivação é o processo pelo qual o indivíduo transforma a ideia de um conceito para algo concreto. Deste modo, os comportamentos relacionados aos cuidados paliativos e os significados que ele traz para determinado grupo parte da forma como o sujeito ancora suas ideias (Moscovici, 2012).

A incongruência nos estimula a nos debruçar sobre a teoria das representações sociais, não somente para nos apropriar do conteúdo teórico, mas tomar conhecimento de sua aplicabilidade e benefícios e critérios bases para aquela sociedade. A teoria das representações sociais, tornou-se eficiente para compreensão de diversos estudos de diferentes temas de variadas 
áreas de conhecimento. As RS florescem como objeto psicossociológico, se consolidando como um campo teórico pluridisciplinar, que colabora com a explicação de problemas relevantes para a educação, saúde, meio ambiente, entre outros (Camargo, 2005).

Sendo assim, observou-se incipiente os estudos direcionados às representações sociais das práticas psicológicas em cuidados paliativos na terminalidade e luto, durante a Covid-19. Conforme a busca realizada no portal da Capes, sem delimitar as bases de dados e ano de publicação, utilizando-se os descritores "cuidados paliativos" AND "representações sociais" AND "psicologia" AND "Covid-19", evidenciou-se apenas um estudo, embora este não fazia referência à temática proposta. A pesquisa de Melo et al. (2021) se propôs a identificar os significados que idosos em cuidados paliativos atribuíam à morte e à vida, em dois grupos focais com 18 idosos em cuidados paliativos.

Desse modo, entende-se que a formulação deste estudo contribuirá servindo como referência para futuras pesquisas, e levando o pesquisador ao conhecimento e entendimento do trabalho realizado pelos psicólogos hospitalares durante a pandemia da Covid-19, os desafios encontrados, assim como verificar os aspectos mais relevantes e significativos, dado que a Teoria das Representações Sociais oportuniza a aproximação entre o sujeito e o objeto. Um dos conceitos inteirados por Moscovici, é a existência de um conhecimento de senso comum, que consente explicitar determinadas práticas, esse processo é responsável pelo enraizamento social da representação e de seu objeto (Sá, 1995).

Diante do exposto o objetivo geral do presente estudo foi, compreender as Representações Sociais acerca dos Cuidados Paliativos nas práticas de competência do psicólogo hospitalar no contexto pandêmico e específicos; compreender o que esses psicólogos hospitalares entendem acerca de Cuidados Paliativos no contexto pandêmico, sua resposta poderiam incluir quais são as atitudes e técnicas utilizadas voltadas tanto para os pacientes no contexto da pandemia do Covid-19 e conhecer quais as principais demandas hospitalares em cuidados paliativos; e identificar sua atuação frente durante a pandemia do Covid-19.

\section{Metodologia}

Trata-se de um estudo de campo, do tipo exploratório, de coorte transversal, de abordagem multimétodos, fundamentado na teoria das representações sociais. A pesquisa foi desenvolvida com psicólogos hospitalares, na cidade de João Pessoa - Paraíba. A amostra foi do tipo não probabilística, de conveniência, compreendida por 16 psicólogos com idades entre 23 a 60 anos $(M=36,56$; $D P=11,89)$, sendo a maioria do sexo feminino (14), possuindo especialização, mestrado e doutorado $10(62,5 \%)$ e que trabalham em instituições públicas 16 (81\%). No que tange ao tempo de atuação observou-se que houve variação entre 2 a 20 anos, nesse caso, 5 (31,25\%) estão em média há 02 anos; 2 (12,50\%) estão entre 03 a 05 anos e 9 (56,25\%) há mais de 06 anos. Adotou-se como critérios de inclusão: (i) ter idade igual ou superior a 18 anos e (ii) e ter atuado durante a pandemia da Covid-19 em instituições hospitalares.

Quanto aos instrumentos, utilizou-se um questionário sociodemográfico e uma entrevista semiestruturada. O primeiro instrumento objetivou identificar o perfil dos participantes. Os psicólogos responderam a um questionário, composto por questões como: sexo, idade, formação, tempo de atuação e tipo de instituição. Destarte, a entrevista semiestruturada foi realizada para compreender as Representações Sociais acerca dos Cuidados Paliativos nas práticas de competência do psicólogo hospitalar no contexto pandêmico e foi composto pelos seguintes questionamentos: O que o senhor (a) compreender acerca de cuidados paliativos, em sua resposta pode incluir quais são as atitudes/ técnicas utilizadas voltadas tanto para os pacientes quanto aos familiares, principalmente nesse momento de pandemia da Covid-19? Quais as principais demandas hospitalares em cuidados paliativos? Como tem sido sua atuação frente ao processo de terminalidade e luto tanto em relação ao paciente, quanto ao familiar? 
Salienta-se que a pesquisa foi aprovada pelo Comitê de Ética em Pesquisa do Instituto de Educação da Paraíba UNIESP, sob parecer $n^{\circ}$ 4.864.630 e CAAE 48727121.6.0000.5184. Durante a sua realização, foram respeitadas todas as condições éticas estabelecidas pela Comissão do Conselho Nacional de Saúde, criada pela Resolução 466/2012.

No que tange ao procedimento de coleta dos dados, com o intuito captar obter um maior número de participantes que se dispusessem a contribuir voluntariamente para esse estudo, foi realizada uma busca ativa nas redes sociais, e aos que sinalizavam o interesse em participar, dialogando entre si, uma possível data e hora para a realização da reunião para a coleta de dados em modalidade remota, aplicando recursos tecnológicos de plataformas digitais de vídeo conferência (Google Meet).

Em outro momento, também foram realizados em acordo com a disponibilidade e condições propícias, o modelo presencial em complexos hospitalares e maternidade na cidade de João Pessoa - PB. Para isso foi necessário entrar em contato com a Secretaria de Saúde, para a realização dos procedimentos de protocolos administrativos e posteriormente com os Centros de Estudos das instituições. Após aprovação do projeto de pesquisa, foi emitida a autorização para adentrar no interior desses locais e direcionamentos aos psicólogos colaboradores do estudo. Esse modelo de coleta fez-se necessário além do cumprimento dos protocolos administrativos, assim também, total obediência às normas de segurança em virtude da pandemia da Covid-19. Todos os participantes assinaram o Termo de Consentimento Livre e Esclarecido.

No que se refere à análise dos dados, o material advindo do questionário sociodemográfico foi processado pelo Pacote Estatístico para as Ciências Sociais (SPSS - 21.0), utilizando-se da estatística descritiva (média, desvio padrão e frequências). Os dados coletados a partir das 16 entrevistas, as quais foram gravadas e transcritas na íntegra, originou um corpus que foi processado pelo software IRAMUTEQ (Interface de R pourles Analyses Multidimensionnelles de Texteset de Questionnaires). Este programa informático viabiliza diferentes tipos de análise de dados textuais, desde a lexicografia básica (cálculo de frequência de palavras), até as análises multivariadas (Classificação Hierárquica Descendente [CHD] e análises de similitude), dessa forma, o software estabelece a distribuição do vocabulário de modo naturalmente compreensível e visualmente claro (Camargo \& Justo, 2013).

Na CHD, as palavras são analisadas e organizadas de acordo com sua frequência, significância e ligação entre si, assim, durante a análises de similitude, as palavras que se sobressaem do corpus textual ficam em evidência e em forma decrescente dentro do dendrograma, demonstrando ligações entre si. Para complementar a análise de similitude averiguada pelo dendrograma utilizou-se também a análise de nuvem de palavras. Estas técnicas de análise possibilitam prontamente através de um arquivo de texto (.txt) e denominado Rapport ou corpus e segmentos de texto, que correspondem aos textos originais da entrevista (Camargo \& Justo, 2013).

\section{Resultados e Discussão}

O presente estudo objetivou compreender as Representações Sociais acerca dos Cuidados Paliativos nas práticas de competência do psicólogo hospitalar no contexto pandêmico. Desse modo, apresentar-se-ão os resultados oriundos das análises: Classificação Hierárquica Descendente e Nuvem de Palavras.

\section{Classificação Hierárquica Descendente (CHD)}

Os resultados provenientes das entrevistas e processados pelo software Iramuteq obtiveram um aproveitamento de 80,65\% do total do corpus. No total foram entrevistados 17 psicólogos hospitalares, também designado de unidades de contexto iniciais (UCIs), totalizando 22.183 ocorrências, sendo 1.737 palavras distintas. Ao reduzir o vocabulário às suas raízes, foi encontrado 1.597 radicais analisáveis e 130 unidades de contextos elementares (UCEs), correspondente a fragmentação do corpus textual, com o agrupamento de palavras segundo a sua forma lexical e frequência. 
No dendrograma intitulado "RS acerca dos cuidados paliativos na pandemia do Covid-19" observa-se que na primeira partição é constituída por seis classes distintas, compilando em dois subcorpora. A primeira aglutinou as classes 1, 2, 5 e 6, conceituando "Terminalidade, acolhimento e humanização frente à hospitalização" na qual se subdividiu de um lado a junção das classes 6 e 2 intitulada "Terminalidade e enfrentamento do Covid-19" e do outro a junção das classes 1 e 5 conceituado "Acolhimento e humanização". E do outro lado do dendrograma observa-se o agrupamento das classes 3 e 4 conceituada de “Atuação da psicologia hospitalar nos cuidados paliativos". Na Figura 1, nota-se que o agrupamento dos subcorpora à direita foi resultante de um bloco textual semelhante, o que permite inferir que suas classes possuem significados complementares, afastando-se do discurso das demais classes.

Figura 1. Dendograma da Classificação Hierárquica Descendente do Corpus "RS acerca dos cuidados paliativos na pandemia do Covid-19".

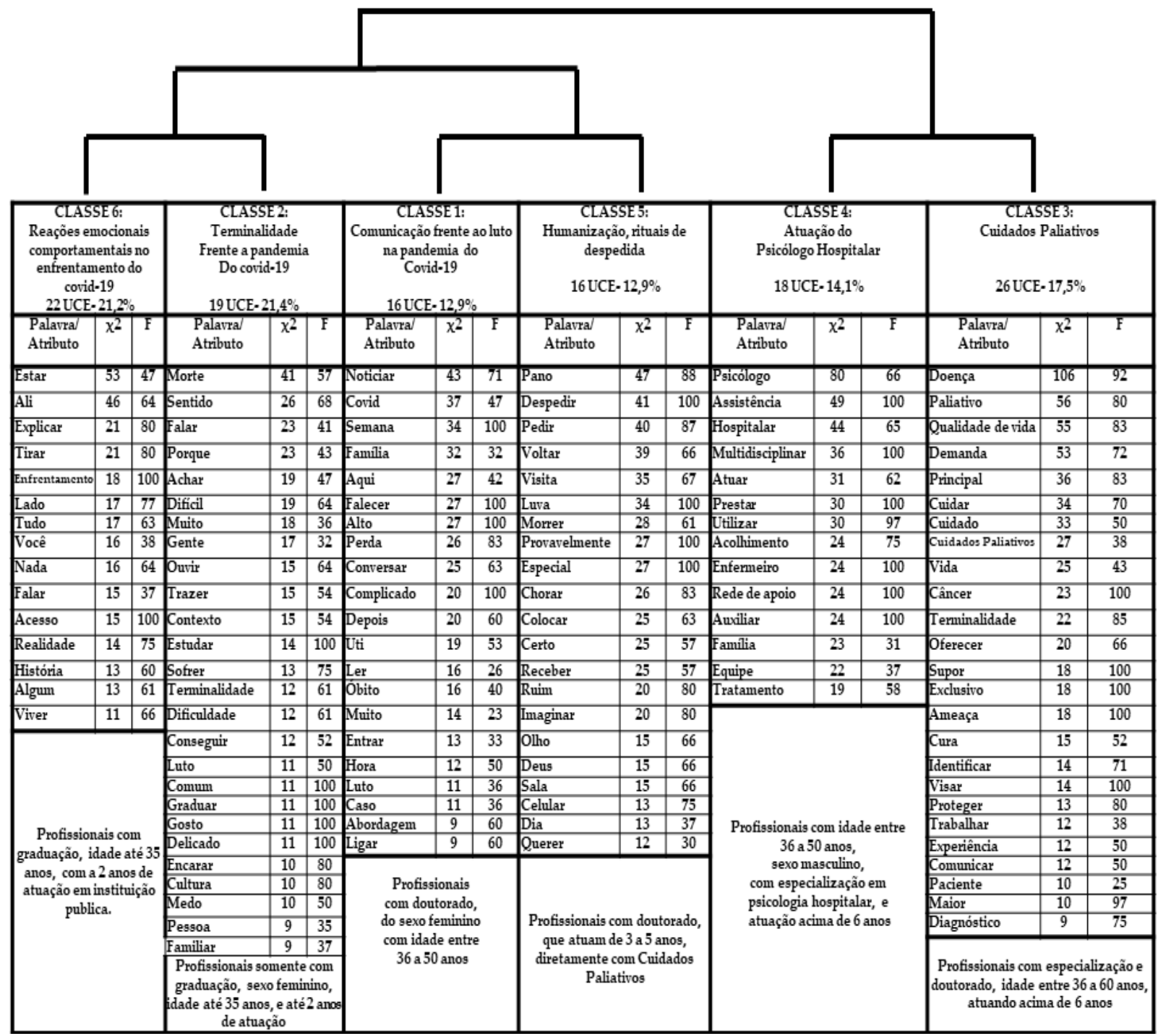

Nota: F: Frequência, X²: Qui- quadrado. Fonte: Autoria Própria

A classe 6, "Relações Emocionais e comportamento no enfrentamento da Covid-19" foi constituída de 22 UCEs, representando $21 \%$ do total do corpus sendo composta por palavra e radicais no intervalo entre $\chi 2=53$ (Estar) e $\chi 2=$ 11(Viver), foi constituída pelo discurso majoritariamente de psicólogos atuantes até 2 anos em instituições públicas. O conteúdo produzido nessa classe suscitado por esses profissionais, ilustraram situações referente às reações emocionais e 
comportamentos no enfrentamento da Covid-19, advindos dos pacientes internados nas enfermarias e UTIs durante a Covid19. A seguir, são listadas algumas pseudofrases emitidas pelos participantes, e que são representativas dessa classe:

"Percebemos que uns preferem não falar nada, outros se desesperam, já tem outros que servem de apoio aos que estão mais abalados, então como eu disse cada um reage de uma maneira" / "Aquele momento com choque como tudo aquilo está acontecendo, e depois a gente tem que parar e explicar à família o por que aconteceu daquela forma e ela não quer entender" / "Uma característica bem legal em CP que é a adaptação, a gente vai adaptar a nossa realidade o cuidar com a necessidade da pessoa então considerando esses aspectos a gente tem tido resultados bem legais e bem positivos"

Diante dos recortes de corpus textuais acima, entende-se que desde o início do tratamento, os envolvidos nesse processo, precisam estar alinhados em informações do estado clínico e emocional do paciente, em vista disso a comunicação na área da saúde é uma ferramenta essencial em todo o percurso do tratamento. Essa comunicação, são compostas por atenção e uma escuta qualificada, assim, esse profissional em posse do conhecimento diante da situação e tomando conhecimento do perfil tanto do paciente quanto da família, é possível traçar formas de intervenções diante de cada caso, e consequentemente estender essas informações aos demais profissionais que compõem a equipe multidisciplinar. Sabendo que cada indivíduo é único em suas emoções, é demandado do psicólogo desdobramento diante dos diferentes impactos emocionais que possam emergir no enfrentamento de adoecimento, iniciando o trabalho de aceitação e elaboração daquela nova realidade da vida deste paciente e familiares. Vale salientar que a comunicação vai muito além das palavras e do conteúdo, uma vez que contempla a escuta atenta, o olhar e a postura, porquanto o emprego eficaz desse recurso é uma medida terapêutica comprovadamente eficiente para pacientes que dele necessitam, sobretudo os que se apresentam em fase terminal (Rodrigues, Ferreira, Menezes, 2010).

Na classe 2 "Terminalidade no contexto da Covid-19", foi constituída de 19 UCEs, representando $21 \%$ do total do corpus sendo composta por palavras e radicais no intervalo $\chi 2=41$ (Morte) e $\chi 2=9$ (Familiar), contribuíram para esse recorte psicólogos graduados, do sexo feminino com idade até 35 anos e dois anos de atuação. Foi possível visualizar que as falas estavam relacionadas ao decurso da terminalidade e morte dificuldades, encontradas nesse processo. Como observa-se nas seguintes pseudofrases:

Muitas das vezes chorei junto com o familiar, e outras nem precisamos falar nada, mas estamos por perto, do lado, tentamos trazer a família para a realidade acolhendo sua dor e tentando amenizar. Esse é o papel do psicólogo diante da morte, entender e avaliar até onde podemos ir. Pra essa prática, porém eu vejo muito mais uma relação de cuidado e de afeto, mas não no sentido de afeto como algo familiar, no sentido de afeto como afeto. Eu sinto que a minha relação, ela é compartilhada com o outro que estar ali na minha frente, então não tem uma superioridade. Então, eu acho um desafio, porque, eu escuto muito falar assim, que tem que apagar incêndio. Você é muito solicitado, não somente pela Inter equipe, mas pela intensificação da equipe para você com o paciente, se intensificam mais, quando se fala em terminalidade, morte e luto, aí eles chamam a psicologia.

Algumas palavras objetivadas pela Classe 2 tais como: "Morte, sentido, falar, difícil, ouvir, sofrer, luto, medo, pessoa, familiar..." ancorou-se na perspectiva do sofrimento que a terminalidade traz para o paciente e para a família, e se potencializou diante da pandemia, dificultando ainda mais esse processo de aceitação e consciência da sua responsabilidade diante do seu próprio tratamento.

Para Mendes (2009), a autonomia fortalecida propicia ao paciente estar ciente de seus deveres e responsabilidades, não se colocando apenas como sujeito passivo diante do processo de adoecimento e morte. E que embora a terminalidade seja um processo natural, entretanto, trabalhar esse assunto com o paciente e a família ainda é de difícil compreensão, visto que a dor da perda geralmente é imensurável considerando o grau de ligação entre os envolvidos nesse processo de final de vida, mesmo que os cuidados paliativos traga o papel de alívio, a família anseia a cura daquela doença, diante disso, o psicólogo 
precisa ter uma postura ética, assertiva e equilibrada no sentido de esclarecer os pontos que envolvem a finitude humana e em especial a daquela pessoa que está finalizando sua vida, dando suporte emocional a quem fica.

Na classe 1, a ancoragem esteve voltada ao conhecimento acerca da "Comunicação frente ao luto na pandemia do

Covid-19" foi constituída de 16 UCEs, representando $12 \%$ do total do corpus sendo composta por palavras radicais no intervalo entre $\chi^{2}=43$ (Noticiar) e $\chi^{2}=9$ (Ligar) fizeram parte desse recorte profissional com doutorado, sexo feminino, idades entre 36 a 50 anos. Como observa-se nas seguintes pseudofrases:

Porque a covid acaba sendo uma doença muito rápida, é muito difícil para as famílias entenderem que, está aqui numa semana, eles souberam notícia naquele dia, que a gente fazia vídeo chamada, fazia tudo, no outro já recebe que está intubado, e talvez, no outro dia, já faleceu. Cuidados paliativos é o que tem na teoria mesmo, a questão dessa morte digna, dentro do hospital quando eles tratam do termo técnico, de chamar a família e conversar é literalmente deixar de investir no paciente. Eu aqui no hospital diariamente com esses casos de covid estou paliando o tempo inteiro e com a dimensão da psicologia e como a medicina também está aliando as duas coisas. Estava naquele sofrimento, mas bastou vir a família ele consegue se desprender. Então muitos pacientes falecem minutos, horas, depois que a família sair. Eu já tive plantão de vivenciar dezessete óbitos no total em um plantão só, então comunicar família, não fiz os dezessete sozinha, mas nessa atmosfera de comunicar família junto com assistente social lidar com aquele processo de receber aquela notícia.

De certo, falar sobre morte e luto geralmente é complicado, visto que nossa cultura não nos prepara para perdas, embora a morte faça parte da vida. E quando a morte é de pessoas próximas, o processo de aceitação é ainda mais difícil, por exemplo perder um familiar na qual possui laços afetivos estreitos, ocasiona dor e a sensação de impotência trazendo uma série de sensações difíceis e sofrimento emocional.

A morte mesmo ocorrendo de forma premeditável, em circunstâncias que propiciaram o processo de entendimento e preparo, diante de um quadro clínico que se apresentou irreversível aos recursos biomédicos, ainda assim, é praticamente impossível que as pessoas não experienciam a dor do luto, seja em alto ou menor grau. De acordo Fonseca (2004), o processo de luto inicia antes mesmo da morte, ou seja, ao tomar conhecimento da própria doença, começam as confusões mentais, sensações de medo, incerteza, estresse, entre outras questões que aparecerão ao longo do processo de adoecimento.

Entretanto durante a pandemia do Covid-19, entre o diagnóstico até os numerosos casos de óbitos que ocorreram em tempo curto, esse processamento e preparo para o enfrentamento da doença ficaram inviáveis, e outras formas de intervenção foram improvisadas, com o objetivo de aproximar o paciente de sua família, já que as visitas foram proibidas em obediência aos protocolos de segurança. Essas novas práticas também foram utilizadas para substituir os rituais de despedidas, algumas vezes momentos em poucas horas antes do paciente ir a óbito. Nesse contexto o psicólogo e a equipe, precisaram interpretar cada momento com um olhar sensível e apurado, diante de cada situação e assim, compreender toda aquela dinâmica para saber o percurso daquela doença e qual seria o limite daquela pessoa para proporcionar a despedida desse paciente com sua família, e assim, facilitar aquele momento "especial", mesmo que fosse a distância através de um vídeo chamada ou ligações utilizando um aparelho tablet ou celular. Para Wallace et al. (2020) a pandemia trouxe medo e dificultou os rituais de despedida, intensificando o medo do presente e ansiedade diante da incerteza do futuro, e nesse contexto salienta-se a importância do acompanhamento psicológico a esta família enlutada.

$\mathrm{Na}$ classe 5, a ancoragem esteve voltada ao conhecimento acerca do "Humanização nos rituais de despedida" foi constituída de 16 UCEs, representando $12 \%$ do total do corpus sendo composta por palavras radicais no intervalo entre $\chi^{2}=$ 47 (Pano) e $\chi^{2}=12$ (Querer) fizeram parte desse recorte, profissional com doutorado, sexo feminino, atuando de 3 a 5 anos. As palavras ancoraram nas questões de humanização e acolhimento no momento da despedida, diante as mortes durante a pandemia do Covid-19. 
E ela me olhou e ela se permitiu chorar. Ela me disse muito obrigada por me ter deixado entrar, aquilo me ajudou a me sentir mais forte. Esse paninho me acompanha desde bebê e entrar pra ver a minha mãe, pra me despedir da minha mãe com ele, me deu todo um sentido diferente. Como as visitas presenciais estavam proibidas, nós começamos fazer as visitas por vídeo chamadas através do tablete, e muitas dessas visitas serviam como despedida, já que o paciente não ia voltar. Mãe, anda sai daí eu estou te esperando em casa já arrumei o quarto, a gente está te esperando, você é forte, você vai sair... Aí eu escutando aquela mulher, eu imaginei que ela não sabe que a mãe dela vai morrer provavelmente até amanhã. A paciente já estava em um processo de inchaço e eu não queria tocar naquela mulher não, mas naquele momento eu entendi que o meu papel passava por aquilo, eu precisava personificar a filha dela ali enquanto a filha dela não estava, então eu fiz e aquela mulher chorou muito se despediu.

O Psicólogo hospitalar, ao desenvolver seu papel, precisa adquirir a compreensão para interpretar além do que é dito, mas também o que está implícito, onde muitas das vezes o que não é dito, pode ter um peso significativo maior até mesmo do que foi verbalizado. Entender que pequenos detalhes podem trazer um significado imensurável para aquelas pessoas, compreender o simbólico, o histórico familiar e o emocional, lembranças boas ou não, porém pertencente a trajetória de vida daquela família. Para a ANCP (2009), o psicólogo neste contexto deve estar atento às necessidades do paciente e família, identificar anseios, medos, valores culturais, e espirituais. mediando questões pendentes, como despedidas, agradecimentos, reconciliações, ou seja, sendo um facilitador entre o paciente, família e equipe.

Na classe 4, a ancoragem deu-se ao conhecimento acerca da "Atuação do Psicólogo Hospitalar" e foi constituída de 18 UCEs, representando $14 \%$ do total do corpus sendo composta por palavras radicais no intervalo entre $\chi 2=80$ (Psicólogo) e $\chi 2=19$ (Tratamento) fizeram parte desse recorte profissionais com especialização em Psicologia Hospitalar, sexo masculino, idades entre 36 a 50 anos e atuando acima de 6 anos. As palavras dessa classe de palavras ancoraram na atuação do psicólogo hospitalar durante a pandemia do Covid-19.

Nós psicólogos hospitalares trabalhamos com algumas intervenções que podem começar com uma escuta ativa, uma intervenção psicoterápica de apoio e também alguns exercícios de psicoeducação dependendo de cada caso. A assistência que o psicólogo presta aos pacientes que estão vivenciando a fase terminal da vida é de ajudar a compreender sua real situação e a lidar com as questões relacionadas à morte. A família é um quadro muito complicado tem alguns familiares que entendem a perda, já terão outros familiares que não irão entender, tem familiar que tenta colocar a culpa na equipe multidisciplinar e já tem familiar que vai dizer poderia ter feito mais e deveria ter cuidado antes, deveria ter prestado atenção na finalização que o paciente estava dando, e outros dizem que a morte só quer uma desculpa.

Assim, espera-se da atuação do psicólogo hospitalar que uma escuta ativa, sendo ela, verbal ou não verbal, ao paciente e a família, aumentará a capacidade de entendimento e irá fortalecer o emocional para lidar com todo o contexto vivenciado, e preparar o seu organismo para responder ao tratamento biomédico da melhor maneira. A escuta permite ao psicólogo identificar as reais demandas do paciente (Othero \& Costa, 2007). O oferecimento de um sistema de suporte à família que facilite a compreensão do processo da doença em todas as fases visa diminuir o impacto que os sintomas psicológicos do doente causam a mesma (Menezes et al., 2007).

Na classe 3, a ancoragem desta está ligada ao conhecimento acerca dos "Cuidados Paliativos" e foi constituída de 26 UCEs, representando $17 \%$ do total do corpus sendo composta por palavras radicais no intervalo entre $\chi^{2}=106$ (Doença) e $\chi 2$ = 9 (Diagnóstico) fizeram parte desse recorte profissionais com especialização e doutorado em Psicologia Hospitalar, idades entre 36 a 50 anos e atuando acima de 6 anos. Esse grupo contemplou discursos que evidenciaram sobre os Cuidados Paliativos na qualidade de vida do paciente com prognóstico inviável à cura, logo algumas pseudo frases:

Cuidado Paliativo é uma abordagem que visa promover melhor qualidade de vida dos pacientes independente de idade e de familiares ou acompanhantes que passam por problemas associados a doenças que ameaçam a continuidade da vida, avaliando e tratando sintomas físicos, psíquicos, sociais e espirituais. Cuidados paliativos são cuidados voltados para minimizar o sofrimento causados por doenças ou situações que ameaçam a vida do paciente, em qualquer idade, 
classe social, visando uma melhor qualidade de vida. As principais demandas hospitalares em cuidados paliativos eram referentes a quadros oncológicos, na minha prática eu via muito essa questão de doenças que progrediram lentamente, agora com a Covid-19, estamos recebendo muito a questão da escuta.

Mediante aos recortes das falas, se evidencia a importância dos CP como uma prática que oferece ao paciente dignidade, autonomia, respeito diante aos seus anseios não somente para morrer, mas conseguir seguir "vivo" durante o percurso daquela doença que ameaça sua vida. Dentre as objetivações dessa classe as expressões mais evocadas; "doença", "cuidados paliativos", "qualidade de vida", "Terminais", ilustra que essa prática continuou sendo promovida mesmo diante do contexto da pandemia do Covid-19, com adaptações para atender os novos modos operantes imposto pela dinâmica do coronavírus.

Mesmo diante do tratamento medicamentoso oferecido ao paciente, existe a constante iminência do controle de sintomas. Esse paciente ao perceber uma piora no seu quadro clínico, começa a surgir sentimentos de medo e angústia, e é natural que seus pensamentos venham o sentimento de morte, em virtude disso, existe a necessidade de intervenção do psicólogo hospitalar para que esse paciente receba apoio emocional se fortalecendo quanto diante do seu diagnóstico, trazendo esse cuidado também a sua família e equipe multidisciplinar, cuidado esse que não pode estar pautado apenas em intervenções técnicas, paliar é fazer mais, é estar o junto daquela pessoa no momento mais difícil de sua existência, seu processo de adoecimento e finitude. Então, estender esse cuidado no apoio às famílias, que após a partida restando a sensação de vazio deste familiar. em especial no período de pandemia onde muitos desses momentos finais da vida do paciente, a família não pode estar junto a ele, ficando ali, o sentimento de total impotência e inconformismo por não poder acompanhar de perto os últimos momentos e despedir-se. Essas interações face a face são consideradas importantes nos chamados "rituais de despedida", isto é, processos de despedida realizados entre pessoas na iminência da morte e seus familiares (Lisbôa \& Crepaldi, 2003).

\section{Nuvem de Palavras}

Para complementar a análise da CHD, utilizou-se também a análise de nuvem de palavras conforme Figura 2.

Figura 2. Nuvem de palavras acerca dos cuidados paliativos na pandemia do Covid-19



Fonte: Autoria Própria. 
Observa-se na Figura 2, a nuvem de palavras que esta emergiu em concordância com a análise hierárquica descendente, evidenciando-se a estrutura do conteúdo em relação às Representações Sociais acerca dos Cuidados Paliativos na terminalidade e luto durante a pandemia do Covid-19, onde destacaram as objetivações mais frequentes: "Gente, Paciente, Muito, Cuidados Paliativos, Pessoa, Falar, Esta, Processo, Família, Covid, escuta, luto", que estão ligadas a importância da prática dos $\mathrm{CP}$ no processo de adoecimento, evidenciando seus princípios no que se refere ao acolhimento e cuidado. Nesse sentido prover o alívio da dor e sintomas, promovendo a escuta e suporte ao paciente, equipe e família, durante todo o processo de adoecimento, terminalidade e luto, compreendendo a subjetiva e individualidade daquela pessoa e respeitando as suas necessidades, oferecendo qualidade de vida até o seu último dia.

Segundo a OMS, o tratamento paliativo deve se iniciar o mais precocemente possível, concomitantemente ao tratamento curativo, utilizando-se todos os esforços necessários para melhor compreensão e controle dos sintomas. Compreende-se que ao buscar o conforto e a qualidade de vida por meio do controle de sintomas, pode-se também possibilitar mais dias de vida (OMS, 2007).

\section{Considerações Finais}

Mediante o estudo transcorrido e de sua análise, em consonância com o objetivo de compreender as representações sociais acerca dos cuidados paliativos de competência do psicólogo hospitalar durante a pandemia da Covid-19, verificou-se que o conhecimento desses profissionais esteve ancorado no saber teórico e prático envolto por aspectos implicativos da pandemia do Covid-19, tanto na perspectiva dos profissionais, familiares e pacientes, vislumbrando fatores como as reações emocionais e comportamentais no enfrentamento e percepção de finitude da vida frente o Covid-19.

Desse modo, pôde-se esmiuçar a importância do papel do psicólogo nas instituições hospitalares tanto públicas quanto privadas. Sendo assim, observou-se que o conteúdo elaborado pelos psicólogos, com ênfase em sua atuação profissional destacaram a importância dessa prática para uma melhor qualidade de vida em todo o processo de adoecimento, desde o diagnóstico até o processo terminal da doença. No que tange ao paciente e família, as verbalizações evidenciaram o processo de acolhimento, envolvendo a escuta, humanização, assistência na subjetividade desse paciente, com o intuito de preservar sua autonomia e apoio ao enfrentamento da doença.

Em relação às práticas profissionais utilizadas, tanto as suas adaptações decorrentes a pandemia da Covid-19, notou-se que psicólogos envolvidos neste estudo em consonância com os demais profissionais que compuseram as equipes multiprofissionais se apropriaram mais uma vez da TRS, onde houve a necessidade de discutir as novas formas de intervenções, esse comportamento ilustrou uma das principais práticas das RS, ou seja, tornar o estranho familiar e o familiar estranho, visto que é imprescindível a continuidade dos CP mesmo em situações emergenciais, assim, criaram-se adaptações a essas práticas do cotidiano hospitalar, facilitando a comunicação entre paciente, equipe e família.

Diante do exposto, neste artigo observou-se durante a coleta de dados que existem poucos profissionais com especialização em cuidados paliativos, notou-se também que mesmo sem a devida formação, a sensibilização perante o sofrimento humano causado pela enfermidade e o risco eminente de morte vivenciada pelo paciente, faz com que o psicólogo se debruce de forma autônoma em busca de conhecimentos, e em consonância com os demais profissionais prestem um atendimento o mais humanizada possível diante das possibilidades e realidades individuais.

Em relação às limitações deste estudo, destaca-se que a utilização de uma amostra não probabilística se revela como uma limitação no que diz respeito à possibilidade de generalização dos resultados. Outras limitações desta investigação deramse em relação às restrições impostas pelo atual momento pandêmico, na qual em alguns casos não foi possível obter autorização para o estudo. Outro fator, deu-se devido à grande carga de trabalho desses profissionais inviabilizando o agendamento para a coleta dos dados, mesmo que remotamente. Outra questão limitante foi o pouco tempo para as entrevistas, 
pois, no caso da modalidade remota o tempo estava cronometrado, e por outro lado, quando realizado presencialmente dentro desses hospitais, era necessário certa brevidade, devido a dinâmica do seu trabalho já que poderiam ser solicitados a qualquer momento para algum atendimento interno.

Espera-se, que tais resultados possam contribuir para futuros estudos diretamente sobre a prática dos CP, vislumbrando despertar sobre sua importância, tanto aos profissionais que exercem dentro de suas atividades, assim como, durante suas formações acadêmicas, favorecendo diálogos e troca de conhecimento. Por fim, entendendo que o trabalho do psicólogo hospitalar está inserido dentro desse contexto e torna-se indispensável sua cooperação em todas essas inquietações ativamente, fazendo com que a psicologia desempenhe o papel de desmistificação e compreensão da importância dos Cuidados Paliativos.

No que tange a perspectiva de estudos futuros, sugere-se o aprofundamento da temática utilizando outros instrumentos de coleta de dados, como é o caso da associação livre de palavras, assim como outros softwares para a análises dos dados, a saber o trideux-mots e o EVOC. Sugere-se ainda, a ampliação do estudo incluindo grupos de pacientes e cuidadores.

\section{Referências}

Academia Nacional de Cuidados Paliativos. (2009). Manual de cuidados paliativos. https://cuidadospaliativos.org/uploads/2020/12/Manual-CuidadosPaliativos.pdf

Angerami-Camon, W. A., Trucharte, F. A. R., Knijnik, R. B., \& Sebastiani, R. W. (1995). Psicologia hospitalar: teoria e prática. In Psicologia hospitalar: teoria e prática (pp. 114-114). https://pesquisa.bvsalud.org/portal/resource/pt/mis-10494

Barreto, M. L., Barros, A. J. D. D., Carvalho, M. S., Codeço, C. T., Hallal, P. R. C., Medronho, R. D. A., \& Werneck, G. L. (2020). O que é urgente e necessário para subsidiar as políticas de enfrentamento da pandemia de Covid-19 no Brasil? Revista Brasileira de Epidemiologia, 23 , e200032. https://doi.org/10.1590/1980-549720200032

Brunoni, A. R. (2020). Jornal da USP - Transtornos mentais podem ter maior recorrência pós-pandemia. https://jornal.usp.br/atualidades/transtornos-mentaispodem-ter-maior-recorrencia-pos-pandemia/

Camargo, B. V., \& Justo, A. M. (2013). Tutorial para uso do software de análise textual IRAMUTEQ. Florianopolis-SC: Universidade Federal de Santa Catarina. http://www.iramuteq.org/documentation/fichiers/tutoriel-en-portugais

Camargo, B. V. (2005). Estratégias de pesquisa pluri-metodológicas. In A. S. P. Moreira, B. V. Camargo, J. C. Jesuíno, \& S. M. Nóbrega (Orgs.), Perspectivas teórico metodológicas em representações sociais (pp. 19-24). Editora Universitária - UFPB.

Chiattone, H. D. C. (2000). A significação da psicologia no contexto hospitalar. Psicologia da saúde: um novo significado para a prática clínica, 2, 145-241. https://pesquisa.bvsalud.org/portal/resource/pt/lil-315605

Domingues, G. R., Alves, K. D. O., Carmo, P. H. S. D., Galvão, S. D. S., Teixeira, S. D. S., \& Baldoino, E. F. (2013). A atuação do psicólogo no tratamento de pacientes terminais e seus familiares. Psicologia Hospitalar, 11(1), 02-24. http://pepsic.bvsalud.org/scielo.php?script=sci_arttext\&pid=S167774092013000100002

Echabe, A. E. (1994). Book Review: Jean-Claude Abric (1994). Pratiques sociales et représentations. Paris: Presses Universitaires de France. Papers on Social Representations, 3, 87-90. http://pepsic.bvsalud.org/pdf/tp/v8n3/v8n3a07.pdf

Farr, R. M. (2009). Representações sociais: a teoria e sua história. In P. Guareschi \& S. Jovchelovitch (Orgs.), Textos em representações sociais (11a ed.), 3159). Vozes. https://doi.org/10.1590/S1414-98932014000100005

Fonseca, J. P. (2004). Luto antecipatório. Campinas (SP): Livro Pleno. https://www.4estacoes.com/pdf/textos_saiba_mais/luto_em_cuidados_paliativos.pdf

Hermes, H. R., \& Lamarca, I. C. A. (2013). Cuidados paliativos: uma abordagem a partir das categorias profissionais de saúde. Ciência \& Saúde Coletiva, 18, 2577-2588. https://www.scielo.br/j/csc/a/6RByxM8wLfBBVXhYmPY7RRB/?format=pdf\&lang=pt

Kovács, M. J. (2008). Desenvolvimento da Tanatologia: estudos sobre a morte e o morrer. Paidéia (Ribeirão Preto), 18(41), 457-468. https://www.scielo.br/j/paideia/a/jQrBZXqtr35w7Y8pqCFcTJH/?format=pdf\&lang=pt

Kübler-Ross, E. (2017). Sobre a morte e o morrer: O que os doentes terminais têm para ensinar a médicos, enfermeiras, religiosos e aos seus próprios parentes. WWF Martins Fontes. https://books.google.com.br/books?hl=pt- BR\&lr=\&id=MDTGDgAAQBAJ\&oi=fnd\&pg=PT3\&dq=K\%C3\%9CBLERROSS, +E.+Sobre+a+morte+e+o+morrer.+S\%C3\%A3o+Paulo:+Martins+Fontes\%3B+2017.\&ots=63B1Xskc6v\&sig=Aeetji2FWNeh6pPe- 
Research, Society and Development, v. 11, n. 3, e43111326655, 2022

(CC BY 4.0) | ISSN 2525-3409 | DOI: http://dx.doi.org/10.33448/rsd-v11i3.26655

o7HqEk3_bg\#v=onepage\&q=K\%C3\%9CBLER-

ROSS $\% 2$ C $\% 20$ E. $\% 20$ Sobre $\% 20 \mathrm{a} \% 20$ morte $\% 20 \mathrm{e} \% 20 \mathrm{o} \% 20$ morrer. $\% 20 \mathrm{~S} \% \mathrm{C} 3 \% \mathrm{~A} 3 \mathrm{o} \% 20$ Paulo\%3A\%20Martins $\% 20$ Fontes $\% 3 \mathrm{~B} \% 202017 . \& \mathrm{f}=$ false

Lisbôa, M. L., \& Crepaldi, M. A. (2003). Ritual de despedida em familiares de pacientes com prognóstico reservado. Paidéia (Ribeirão Preto), 13, 97-109. https://doi.org/10.1590/S0103-863X2003000200009

Melo, C. M., Morais, J. C. C., Medeiros, L. C. L., Lima, A. C. F. B., Bonfim, L. P., \& Martins, J. C. O. (2021). O binômio morte e vida para idosos em cuidados paliativos. Revista da SPAGESP, 22(2), 5-18. http://pepsic.bvsalud.org/scielo.php?script=sci_arttext\&pid=S1677$29702021000200002 \& \operatorname{lng}=$ pt\&tlng=pt.

Mendes, Juliana Alcaires, Lustosa, Maria Alice, \& Andrade, Maria Clara Mello. (2009). Paciente terminal, família e equipe de saúde. Revista da SBPH, 12(1), 151-173. http://pepsic.bvsalud.org/scielo.php?script=sci_arttext\&pid=S1516-08582009000100011\&lng=pt\&tlng=pt.

Menezes, C. N. B., Passareli, P. M., Drude, F. S., dos Santos, M. A., \& do Valle, E. R. M. (2007). Câncer infantil: organização familiar e doença. Revista Subjetividades, 7(1), 191-210. https://periodicos.unifor.br/rmes/article/view/1579/3563

Moscovici, S. (2012). Representações sociais: Investigações em psicologia social. (7a ed.). Vozes. https://dialnet.unirioja.es/servlet/articulo?codigo=6783807

OMS. Organização Mundial da Saúde. (2020). OMS afirma que Covid-19 é agora caracterizada como pandemia. https://www.paho.org/pt/news/11-3-2020who-characterizes-Covid-19-pandemic

OMS. Organização Mundial da Saúde. (2021). Programas nacionais de controle do câncer: políticas e diretrizes gerenciais. Organização Mundial da Saúde. https://books.google.com.br/books?hl=pt-

BR\&lr=\&id=7VQ0DgAAQBAJ\&oi=fnd\&pg=PR11\&dq=WHO.+World+Health+Organization.+National+cancer+control+programmes:+policies+and+manag erial+guidelines.+Geneva:+WHO,+2002\&ots=qggyYi-gVB\&sig=kx6bb7ZfP7-aoB5ihIRs3xEo-

$\mathrm{vY} \# \mathrm{v}=$ =nepage \&q=WHO.\%20World\%20Health\%20Organization.\%20National\%20cancer\%20control\%20programmes\%3A\%20policies\%20and\%20manager ial\%20guidelines. $\% 20 \mathrm{Geneva} \% 3 \mathrm{~A} \% 20 \mathrm{WHO} \% 2 \mathrm{C} \% 202002 \& \mathrm{f}=$ false

Othero, M. B., \& Costa, D. G. (2007). Propostas desenvolvidas em cuidados paliativos em um hospital amparador-Terapia Ocupacional e Psicologia. Pratica Hospitalar, 9(52), 157-60. https://paliativo.org.br/wp-content/uploads/download-manager-files/ph_terapiaocupacional_psicologia.pdf

Rodrigues, M. V. D. C., Ferreira, E. D., \& Menezes, T. M. D. O. (2010). Comunicação da enfermeira com pacientes portadores de câncer fora de possibilidade de cura. Revista de enfermagem. UERJ, 86-91. https://pesquisa.bvsalud.org/portal/resource/pt/lil-166531

Rodrigues, E. S., \& Souza, M. M. M. (2015). A inclusão dos pacientes em estado terminal pelo viés da atuação da Psicologia Hospitalar. Brasil Para TodosRevista Internacional, 2(1), 96-100. https://ojs.eniac.com.br/index.php/Anais_Sem_Int_Etn_Racial/article/view/258

Sá, C. P. (2015). Teoria e pesquisa do núcleo central das representações sociais. Sá CP, organizador. Estudos de psicologia social: história, comportamento, representações e memória. Rio de Janeiro: Ed UERJ, 209-26.

Santos, F. S. \& Incontri, D. (2009). A Arte de Morrer: Visões Plurais. (2a ed.), Editora Comenius, 2009.

Wallace, C. L, Wladkowski, S. P, Gibson, A., \& White, P. (2020). Luto durante a pandemia de Covid-19: considerações para prestadores de cuidados paliativos. Journal of Pain and Sintoma Management, 60 (1), e70-e76.http://dx.doi.org/10.1016/j.jpainsymman.2020.04.012.

Zhou, P., Yang, X. L, Wang, X. G, Hu, B., Zhang, L., Zhang, W., \& Shi, ZL (2020). Descoberta de um novo coronavírus associado ao recente surto de pneumonia em humanos e seu potencial origem em morcegos. Bio Rxiv https://doi.org/10.1101/2020.01.22.914952 